\title{
Agent-based modeling of complex social-ecological feedback loops to assess multi-dimensional trade-offs in dryland ecosystem services
}

\author{
Takafumi Miyasaka $\cdot$ Quang Bao Le $\cdot$ Toshiya Okuro • \\ Xueyong Zhao $\cdot$ Kazuhiko Takeuchi
}

Received: 8 September 2016/ Accepted: 9 February 2017/Published online: 23 February 2017

(C) The Author(s) 2017. This article is published with open access at Springerlink.com

\begin{abstract}
Context Recent conceptual developments in ecosystem services research have revealed the need to elucidate the complex and unintended relationships between humans and the environment if we are to better understand and manage ecosystem services in practice.

Objectives This study aimed to develop a model that spatially represents a complex human-environment (H-E) system consisting of heterogeneous socialecological components and feedback mechanisms at multiple scales, in order to assess multi-dimensional
\end{abstract}

Electronic supplementary material The online version of this article (doi:10.1007/s10980-017-0495-x) contains supplementary material, which is available to authorized users.

T. Miyasaka $(\bowtie)$

Institute of Agriculture, Tokyo University of Agriculture and Technology, 3-5-8 Saiwai-cho, Fuchu-shi,

Tokyo 183-8509, Japan

e-mail: miyataka@cc.tuat.ac.jp;

bremen_de@hotmail.com

Q. B. Le

CGIAR Research Program on Dryland Systems, International Center for Agricultural Research in the Dry Areas (ICARDA), Amman 11195, Jordan

\section{Q. B. Le}

Institute for Environmental Decisions, Swiss Federal Institute of Technology Zurich, Universitaetstrasse 22, 8092 Zurich, Switzerland (spatial, temporal, and social) trade-offs in ecosystem services.

Methods We constructed an agent-based model and empirically calibrated it for a semi-arid region in Northeast China, and examined ecosystem service trade-offs derived from the Sloping Land Conversion Program (SLCP), which is based on payment for ecosystem services. This paper describes our model, named Inner Mongolia Land Use Dynamic Simulator (IM-LUDAS), using the overview, design concepts, and details + decision $(\mathrm{ODD}+\mathrm{D})$ protocol and demonstrates the capabilities of IM-LUDAS through simulations.

Results IM-LUDAS represented typical characteristics of complex H-E systems, such as secondary and cross-scale feedback loops, time lags, and threshold

\footnotetext{
T. Okuro

Graduate School of Agricultural and Life Sciences, The

University of Tokyo, 1-1-1 Yayoi, Bunkyo-ku,

Tokyo 113-8657, Japan

X. Zhao

Cold and Arid Regions Environmental and Engineering

Research Institute, Chinese Academy of Sciences, 260

Donggang West Road, Lanzhou 730000, People's

Republic of China

K. Takeuchi

Integrated Research System for Sustainability Science,

The University of Tokyo, 7-3-1 Hongo, Bunkyo-ku,

Tokyo 113-8654, Japan
} 
change, revealing the following results: tree plantations expanded by the SLCP facilitated vegetation and soil restoration and household change toward off-farm livelihoods, as expected by the government; conversely, the program caused further land degradation outside the implementation plots; moreover, the livelihood changes were not large enough to compensate for income deterioration by policy-induced reduction in cropland.

Conclusions IM-LUDAS proved itself to be an advanced empirical model that can recreate essential features of complex H-E systems and assess multidimensional trade-offs in ecosystem services.

Keywords Cost-effective targeting .

Desertification - Economic structural shift - Grain for Green · Heterogeneity · Hierarchy · Horqin Sandy

Land · Inner Mongolia · Multi-agent system · Spatiotemporal externality

\section{Introduction}

The concept of ecosystem services has drawn attention in the past two decades, particularly since the Millennium Ecosystem Assessment (MA) report in 2005, as a crucial bridge between human society and the environment (de Groot et al. 2010; Reynolds et al. 2011; $\mathrm{Wu}$ 2013). The MA provided a conceptual framework for holistic approaches that integrate ecological, economic, and institutional perspectives, and aimed to answer policy-relevant questions on the sustainable use of natural resources (MA 2005). The concept of ecosystem services has become a guiding principle in resource management and relevant policies ( $\mathrm{Wu}$ 2013), and more elaborate conceptual frameworks have been developed, such as Intergovernmental Platform on Biodiversity and Ecosystem Services (IPBES) Conceptual Framework (Díaz et al. 2015). Nevertheless, progress in using the concept in practice remains insufficient (Bennett et al. 2015). According to Bennett et al. (2015), this gap is mainly due to two reasons: knowledge on ecosystem services is fragmented into many disciplinary studies and not well integrated; and most research on ecosystem services is conceptual or deals with only one aspect of the interaction between people and ecosystems. Indeed, unintended outcomes often arise from actual management options, many of which are grounded in untested assumptions and depend on sparse information rather than holistic empirical analysis (Carpenter et al. 2009). Further integrated research is therefore needed to better understand and manage ecosystem services, by elucidating the complex, unintended relationships between humans and the environment (Holling 2001; Turner et al. 2003; Carpenter et al. 2009; Li et al. 2015). In this context, coupled human-environment (H-E) systems, also called social-ecological systems, can be a useful integrated analytical framework (Ostrom 2007, 2009; Reynolds et al. 2007, 2011; Scholz 2011a).

H-E systems are complex and adaptive systems characterized by non-linearity, self-organization, and co-evolutionary dynamics resulting from continuous adaptation and learning at multiple scales (Levin 1998; Rammel et al. 2007). The continuous adaptation and learning-feedback loops between human and environmental systems - are based on the collection of heterogeneous system components interacting with each other. Human and environmental systems are intrinsically heterogeneous. Individual humans are different, having their own assets, thinking processes, and behaviors, while landscapes are a mosaic of different types of land use and cover, topography, soil, and vegetation. Various social and ecological processes also occur heterogeneously on the basis of the diverse components in both types of system. Social and ecological heterogeneity, as well as hierarchy and feedback mechanisms, are therefore essential factors of complex systems (Liu et al. 2007a, b; Le et al. 2008, 2010; Verburg and Overmars 2009; Villamor et al. 2011; Le et al. 2012). At the same time, the combination of heterogeneity, hierarchy, and feedback mechanisms complicates $\mathrm{H}-\mathrm{E}$ systems and makes them difficult to understand.

This difficulty in understanding H-E systems is one of the major challenges in ecosystem services research. Ecosystem services are inherently related to each other via coupled feedback loops in space and time. If people try to optimize a single ecosystem service, other services can also be affected in adverse and unintended ways. These "ecosystem service trade-offs" can occur in spatial, temporal, and social dimensions (Boulanger and Brechet 2005; Seppelt et al. 2011). The trade-offs do not always occur in the same place or immediately after human intervention. Their emergence can be spatially dislocated or 
temporarily delayed. For instance, management decisions often focus on the immediate provision of an ecosystem service in a place, but they could reduce the same or other services in other places or in the future. The trade-offs become an issue when multiple ecosystem services respond differently to human activities (Rodríguez et al. 2006; Seppelt et al. 2011), bringing people not only benefits but also negative consequences. Moreover, a change in an ecosystem service may not equally affect people in a variety of socioeconomic circumstances. Understanding multi-dimensional trade-offs in ecosystem services, while factoring in social-ecological diversity and interactions at multiple scales, is a major challenge in ecosystem services research and is crucial for making appropriate decisions in practice (Carpenter et al. 2006, 2009; Rodríguez et al. 2006; de Groot et al. 2010; Seppelt et al. 2011; Verburg et al. 2013; Bennett et al. 2015).

Although a spatially-explicit, integrated-modeling approach has been used to model complex socialecological dynamics and subsequent ecosystem service trade-offs (Liu et al. 2008), recent reviews have showed that many contemporary modeling methods were not able to capture mutual trade-offs over spatial, temporal, and social dimensions (Boulanger and Brechet 2005; Kelly et al. 2013; Le 2015). System dynamics models are strong in representing social-ecological dynamics and temporal trade-offs, but rather weak in addressing socialecological heterogeneity and subsequent spatial trade-offs. Spatial optimization models are capable of detecting spatial trade-offs, but have less potential to anticipate temporal ones (Boulanger and Brechet 2005). Spatial Bayesian Network models are excellent for coping with the uncertainty of social-ecological interrelationships, but have poor capacity to understand or represent complex tradeoffs, because when used alone they do not incorporate feedback loops (Kelly et al. 2013). These conventional spatial modeling approaches do not explicitly represent individual actors, and thereby do not, in principle, capture trade-offs in heterogeneous human communities and landscapes (Boulanger and Brechet 2005; Le 2015).

For the last decade, agent-based modeling (ABM) has been adopted extensively to understand $\mathrm{H}-\mathrm{E}$ systems (Li 2012). ABM uses computerized, bottomup simulations of entire landscape patterns emerging from interactions among autonomous entities, which have their own internal conditions and behavioral rules, and are embedded in a dynamic spatial environment that supports or regulates their activities. ABM offers a way of incorporating heterogeneous human and environmental entities and feedback loops at multiple scales in a spatially-explicit manner (Matthews et al. 2007). This modeling structure is well-suited to represent the characteristics of $\mathrm{H}-\mathrm{E}$ systems, and spatio-temporal simulation with ABM is capable of assessing ecosystem service trade-offs (Boulanger and Brechet 2005; Le 2015).

This study aimed to develop a spatial, agent-based model that represents a complex H-E system, which consists of social-ecological heterogeneous components and feedback mechanisms at multiple scales, and enables the assessment of multi-dimensional tradeoffs in ecosystem services. We empirically calibrated the model for a semi-arid desertified region in Inner Mongolia, China. Desertification is a classic example of problems in H-E systems (Whitfield et al. 2011). Although most desertification estimates have been made solely using either ecological or socioeconomic factors, close relationships between human livelihoods and the environment in drylands indicate the need to focus on the H-E systems (Reynolds et al. 2007, 2011). In Inner Mongolia, most scientific research has focused on natural science topics (e.g., soil, vegetation, and their interactions), and the need to balance economic, social, and environmental aspects have been also pointed out (König et al. 2014). We therefore modeled the balance between local people's livelihoods and the degradation and restoration of soil and vegetation, derived from a payment for ecosystem services (PES) program called the Sloping Land Conversion Program (SLCP).

A specific research question on our model building was based on the context of the SLCP. Although we provide the general description of the policy in the next section, it is a cropland set-aside policy and aims to alleviate poverty and promote local economic development as well as to prevent soil erosion and restore the environment, by restricting agriculture and providing a subsidy (State Forestry Administration 2003). The official site-selection criterion, however, is only the steepness of land. Other social and ecological factors, such as the level of poverty and land degradation, are not explicitly considered when choosing target households and plots. Since budgets 
are always limited, it would be better that the policy focus on degraded cropland, particularly in desertified regions, and poor households at certain levels of degradation and poverty. Earlier research has therefore indicated that the cost-effectiveness of the policy in terms of environmental benefits and poverty alleviation should be considered on the basis of social and ecological heterogeneity, in order to make it more effective and to achieve its overall goals (Wang et al. 2007a, b; Uchida et al. 2009; Chen et al. 2010; Gauvin et al. 2010).

Related to the abovementioned multiple aims of the SLCP, researchers have indicated a need to assess a potential effect of the policy that the government expects: inducing shifts in economic structure, especially from an agricultural to a non-agricultural economy, to reduce economic instability resulting from the overuse of vulnerable natural resources (Uchida et al. 2009; Li et al. 2011), and thereby, to reduce future environmental degradation. $\mathrm{H}-\mathrm{E}$ system perspectives are essential for clarifying these SLCP's long-term social-ecological impacts. Feedback mechanisms in coupled systems, for example, need to be addressed to examine potential structural changes in the economy, along with environmental change. However, the complexity of the SLCP's impacts is poorly understood because of the lack of integrated assessment frameworks (Liu et al. 2008; Yin and Zhao 2012).

In the above context, we built an integrated model to answer the following research question: Can the Sloping Land Conversion Program (SLCP) better achieve its multiple goals, including economic structural shift, if targeting strategies based on social and ecological heterogeneity are incorporated into it? We designed our model to enable the assessment of different targeting strategies and the policy's complex effects by dynamically linking the social and ecological components with consideration of their heterogeneity.

In this paper, we describe our model, named IMLUDAS (Inner Mongolia Land Use Dynamic Simulator), using the overview, design concepts, and details + decision (ODD + D) protocol (Müller et al. 2013). Then, we demonstrate simulation results that show the capability of IM-LUDAS for answering the research question on the basis of the assessment of multi-dimensional trade-offs in ecosystem services in a dryland H-E system.

\section{Model development}

\section{General rules of Sloping Land Conversion Program (SLCP)}

PES programs have recently become a key policy mechanism to protect, restore, or enhance ecosystem services. They have also attracted attention as a way of contributing to poverty alleviation by making payments to poor service suppliers and creating diversified livelihood opportunities (Pagiola et al. 2005).

China's SLCP, one of the world's largest PES programs, is a cropland set-aside policy implemented throughout the country. In principle, the implementation plots to convert from cropland to tree plantations are selected from steep land, which is defined as land with a slope gradient of 25 degrees or more in the upper reaches of the Yangtze River (southern China) and 15 degrees or more in the middle and upper reaches of the Yellow River (northern China). The government offers participating farmers 2250 and $1500 \mathrm{~kg}$ of grain (or 3150 and 2100 yuan [exchange rate 1 U.S. dollar $=6.88$ yuan on 27-January-2017] at 1.4 yuan per kg of grain) per ha of converted cropland per year in southern and northern China, respectively. In addition, 300 yuan per ha per year is provided to participants for miscellaneous expenses. The duration of the subsidy depends on the options of cropland conversion: 2 years if the cropland is converted into grassland, 5 years if converted into economic forest (e.g., orchards), or 8 years if converted to ecological forest (e.g., windbreak forests). In 2007, the government extended the policy for another round of two to eight years, depending on the above conversion types. The annual compensation during the extension is half of the amount in the first round, but the 300 yuan for miscellaneous expenses remains the same. In principle, forestland in China, including tree plantations, is not allowed to be converted to another land use.

Study area

The study area was located in the central part of Naiman County, an agro-pastoral region of Inner Mongolia, in northeast China $\left(42^{\circ} 55^{\prime} \mathrm{N}, 120^{\circ} 42^{\prime} \mathrm{E}\right)$. The elevation of the site is approximately $360 \mathrm{~m}$ above mean sea level. The region is in a temperate zone with a continental semi-arid monsoon climate, with the highest rainfall occurring in the summer 
months, and dry and windy conditions prevail in springtime. The mean annual precipitation is approximately $360 \mathrm{~mm}$, mainly falling between June and August. The mean annual temperature is $6.4{ }^{\circ} \mathrm{C}$, with the coldest and warmest monthly mean air temperatures being in January $\left(-13.1^{\circ} \mathrm{C}\right)$ and July $\left(23.7^{\circ} \mathrm{C}\right)$, respectively.

In recent decades, this region has undergone severe desertification, primarily due to heavy pressure on productive natural resources, such as over-grazing and over-cultivation driven by a rapidly growing human population (Zuo et al. 2010). The area is now called the Horqin Sandy Land, known as a major desertified region in China. Along with the decrease of vegetation cover and the deterioration of soil physiochemical properties, land conditions change from stable to unstable in the dry and windy climate. Those changing land conditions are typically reflected by classification as fixed, semi-fixed, or shifting sandy land. Since the shifting sandy land-with little vegetation and poor soil nutrients-does not favor production activities, an expansion of the shifting sandy land generally indicates the loss of ecosystem services.

Topography is a crucial factor for characterizing land degradation and restoration. The topography in the study area is classified into three types: lowlands, flat sandy lands, and sand dunes (sloping sandy lands) (Okuro 1997). If people graze their livestock, the extent of land degradation brought about by the activity differs significantly depending on topographic type. To begin with, sand dunes are generally more susceptible to wind erosion than flatland (i.e., lowland and flat sandy land) because of their convex shape and lower soil water content. Lower soil moisture leads to decreasing threshold of friction velocity and resistance to wind erosion (Marticorena et al. 1997). When grazing livestock, surface soil on a slope is more prone to being disturbed and dug than that on flatland and then become more vulnerable to wind erosion (Okuro 1997). In addition, according to Miyasaka et al. (2011), the local cropping system is closely related to the topographic types: maize plantations need large fertilizer inputs and are basically restricted to flatland where irrigation is possible; on lowland, however, maize is grown, with little or no irrigation required thanks to favorable soil moisture conditions; on sand dunes, bean-centered rotational cropping is practiced, with a small amount of fertilizer applied, taking advantage of the ability of legumes to fix nitrogen in the soil. Changes in crop growth generally occur in soils with properties altered by wind erosion, but crops are also influenced directly by harsh winds; seedlings suffer from abrasion and burial during storms and then often die because of reduced photosynthesis, the weight of the sand deposits, and high daytime soil temperatures (Sterk and Haigis 1998). Miyasaka et al. (2011) showed that the patterns of land degradation and productivity decline differ significantly with the type of cropland. The biomass of both maize and beans decreased notably with increasing cultivation, but the highest rate of decrease was observed in bean-centered cropland, whereas the lowest rate of decrease was in maize cropland on flat sandy lands. This is because of differences in topographic erodibility and irrigation practice, which significantly improves soil moisture, between the three cropland types. Furthermore, Miyasaka et al. (2014) found a process of land restoration characterized by topography. Diaspores are provided mainly from nearby aboveground communities in this area. These transported diaspores are likely to initially germinate in flat sandy lands surrounded by sand dunes. Such lands have advantages, such as higher water availability and protection from harsh winds, allowing them to gradually spread to the top of sand dunes. This process indicates that restoration on sand dunes is delayed and takes more time compared to flat sandy lands. Miyasaka et al. (2014) also demonstrated that the planting of trees, which is promoted by the SLCP, resulted in the restoration of understory vegetation faster than simple livestock exclusion and transformed shifting sandy land to fixed sandy land within 25 years.

The following 12 land-use categories used in this study are therefore based on the topographic types, in order to represent the local cropping system and different patterns of land degradation and restoration: maize cropland on flat sandy lands, maize cropland on lowlands, bean-centered cropland on sand dunes, paddy on lowlands, tree plantations on flatlands (including lowlands and flat sandy lands), tree plantations on sand dunes, fixed sandy pasture on flatlands, fixed sandy pasture on sand dunes, semi-fixed sandy pasture on flatlands, semi-fixed sandy pasture on sand dunes, shifting sandy pasture on flatlands, and shifting sandy pasture on sand dunes. The sub-models of IMLUDAS on land degradation and restoration also explicitly consider the effect of topography. 
In Naiman County, we selected two typical administrative villages as research sites, one in which Mongolian and the other in which Han residents were in the majority. Those research sites represent the socioeconomic variations of a much broader area surrounding the sites in which Mongolian and Han peoples are the major ethnic groups. The two administrative villages are composed of five hamlets called natural villages, which have some institutional differences. For instance, land-allocation rules differed among the natural villages, and some policies including the SLCP used them as the organizational unit. The Mongolian village included three natural villages, and the SLCP was implemented in two of them. On the other hand, the Han village included two natural villages and was not subject to the SLCP. All SLCP implementation plots in the two Mongolian natural villages were simultaneously converted to tree plantations in 2003. The first round ended in 2010, and the second round will last from 2011 through 2018 . We hereinafter refer to each of the natural villages as either a "Mongolian village" or "Han village."

The rules of the SLCP differ from region to region. Every household in the two Mongolian villages covered by our study participated in the SLCP. Each person was assigned a quota of two or three $m u$ (15 $m u=1 \mathrm{ha}$ ) for implementation area under the program (e.g., if two mu per person is given to a family of four, the household must execute the program on eight $m u$ of their land). Flatlands tended to be selected as target plots, which was the opposite of the official rule, because they had advantages in land management, including irrigation. The subsidy was provided fully in cash (i.e., 2100 yuan per ha as compensation plus 300 yuan per ha as miscellaneous expenses). Poplar (Populus simonii) was the only species of tree planted to make an ecological forest in our study, and the duration of subsidization for all implementation plots was eight years. Since the amount of compensation is halved in the second round, the total subsidy is $\mathbf{1 3 5 0}$ yuan per ha from 2011.

We classified local household livelihoods into three types: livestock farming, crop farming, and nonfarming. This classification was based on our household survey conducted in the above-mentioned five villages in 2010. Although crop farming is a major income source for all of the livelihood types, they are clearly differentiated by socioeconomic factors, as shown in Table 1. Moreover, between the livelihood types, there are also differences in how local households allocate their labor force to each of the above three economic activities (see Appendix 2). We examined structural change in the local economy by simulating change in livelihoods, represented by the three livelihood types.

Ecosystem services and their indicators

We particularly examined the following ecosystem services in this area: crop and pasture production as provisioning services, and soil erosion control as a regulating service. Those ecosystem services are closely related to the local livelihoods and the SLCP aims. We mainly used the following indicators for the

Table 1 Socioeconomic characteristics of three livelihood types in northeast China

\begin{tabular}{|c|c|c|c|c|c|c|c|c|}
\hline $\begin{array}{l}\text { Livelihood } \\
\text { type }\end{array}$ & $\begin{array}{l}\text { Householder's } \\
\text { age (year) }\end{array}$ & $\begin{array}{l}\text { Householder's } \\
\text { ethnic group } \\
\text { (1: Han, 0: } \\
\text { Mongolian) }\end{array}$ & $\begin{array}{l}\text { Householder's } \\
\text { educational level } \\
\text { (1: higher than } \\
\text { elementary school, } \\
0 \text { : other) }\end{array}$ & $\begin{array}{l}\text { Labor } \\
\text { force } \\
\text { (persons) }\end{array}$ & $\begin{array}{l}\text { Householder's } \\
\text { leadership ( } 1 \text { : } \\
\text { titled }^{\text {a }}, 0 \text { : } \\
\text { other) }\end{array}$ & $\begin{array}{l}\text { Crop- } \\
\text { farming } \\
\text { income } \\
\text { ratio } \\
(\%)\end{array}$ & $\begin{array}{l}\text { Livestock- } \\
\text { farming } \\
\text { income } \\
\text { ratio }(\%)\end{array}$ & $\begin{array}{l}\text { Non- } \\
\text { farming } \\
\text { income } \\
\text { ratio } \\
(\%)\end{array}$ \\
\hline $\begin{array}{r}\text { Livestock } \\
\text { farming }\end{array}$ & 54 & 0.2 & 0.7 & 3 & 0.3 & 56 & 33 & 6 \\
\hline $\begin{array}{l}\text { Crop } \\
\text { farming }\end{array}$ & 53 & 0.7 & 0.4 & 2 & 0.0 & 78 & 7 & 6 \\
\hline $\begin{array}{l}\text { Non } \\
\text { farming }\end{array}$ & 35 & 0.5 & 0.9 & 2 & 0.4 & 41 & 18 & 40 \\
\hline $\begin{array}{l}P \text { value } \\
\text { (ANOVA) }\end{array}$ & 0.000 & 0.000 & 0.002 & 0.000 & 0.004 & 0.000 & 0.000 & 0.000 \\
\hline
\end{tabular}

$\overline{\text { a }}$ Titled householders (sixth column) are the former or present members of a village committee (the self-governing body of an administrative village) or the Chinese Communist Party 
ecosystem services: (1) crop yields for crop production, (2) vegetation cover and plant species composition and diversity for pasture production, and (3) the area of tree plantations and fixed sandy pasture (i.e., the coverage of abundant vegetation preventing soil erosion) for soil erosion control. Crop yields, vegetation cover, and plant species composition and diversity are also good indicators for cropland degradation (Miyasaka et al. 2011), pasture degradation (Okuro 1997), and pasture restoration (Miyasaka et al. 2014), respectively.

Model description with the ODD + D protocol

\section{Overview}

Purpose The purpose of IM-LUDAS is to understand spatio-temporal social-ecological effects, including ecosystem service trade-offs, of the SLCP and alternatives. The model has been designed for scientists and policy makers interested in the complex effects of PES programs on $\mathrm{H}-\mathrm{E}$ systems in general, or in natural resource management and sustainable development in desertified regions of northeast China.

Entities, state variables, and scales IM-LUDAS consists of landscape agents (grid cells in the landscape) and human agents (individual households). The state variables and sub-model parameters of a landscape agent include its location and the following attributes: natural (topographic type, vegetation structure, soil physiochemical properties, and coefficients of variables of the Land Restoration Dynamics sub-model), agricultural (land availabilityfallowed or not, land accessibility, land-use type, area of the land-use plot the agent belongs to, agricultural yield, livestock density, labor force required for the land-use type per year, choice probabilities of potential land-use types, and coefficients of variables of the Agricultural Yield Dynamics, Cropland Degradation Dynamics, and Pasture Degradation Dynamics sub-models), institutional (ownership, village, and SLCP-plot codes), and land history (land-use and SLCP histories). The state variables and sub-model parameters of a household agent include its socioeconomic attributes (location, ownership and village codes, involvement in the SLCP, householder's age, ethnic group, educational level, and leadership, household size, labor force and breakdown for different economic activities, number of owned livestock, structure of landholdings and income, livelihood type, and coefficients of variables of the Land Use Choice sub-model). The location, ownership and village codes, topographic type, householder's ethnic group, educational level, and leadership, and household size are exogenous factors (i.e., stable during a simulation). Space is explicitly considered in the model: distance from a household's house location to each land pixel of its landholdings is a determinant of its land-use decision. As for hierarchy, the landscape agents constitute the landholdings of their owner household agents; the landholdings and household agents constitute village landscapes and population, respectively; and the entire study area is the highest aggregate level of both agents. The area modeled is represented in a grid of approximately $700 \times 1000$ cells based on GIS data, and each cell represents $15 \times 15 \mathrm{~m}$. A simulation is composed of 30 annual cycles from 2010 to 2039 .

Process overview and scheduling IM-LUDAS proceeds in annual time steps (Fig. 1). Initialization and the annual process are broken into 23 steps (procedures and sub-models), which are described in Table 2 and the Appendices. Figure 2 illustrates key functional interactions between the steps (excluding the initialization and observation steps), providing an overall view of modeled $\mathrm{H}-\mathrm{E}$ dynamics, including feedback mechanisms.

\section{Design concepts}

Theoretical and empirical background To comprehensively represent a dryland dynamic system, including environmental and socioeconomic states and changes and their interactions, we used the Hierarchical Patch Dynamics (HPD) paradigm (Wu and Loucks 1995; Wu 1999; Wu and David 2002) and the Human-Environment Systems (HES) framework (Scholz 2011a). The HPD paradigm was originally applied to complex ecological systems but can also explain social-ecological heterogeneity and hierarchy. The HES framework is one of the few general frameworks that explicitly conceptualize feedback loops between human and environmental systems (Binder et al. 2013). These provide a conceptual guideline for comprehensive analysis of complex H-E systems, incorporating key features such as heterogeneity, hierarchy, and different types of feedback loop. For example, the idea of secondary 
Fig. 1 Simulation processes of IM-LUDAS consisting of 23 steps (procedures and submodels). Brief descriptions of those procedures and submodels are provided in Table 2. Main procedures and sub-models are detailed in the Appendices, but the rest are described in detail in Le (2005) and Le et al. (2008)

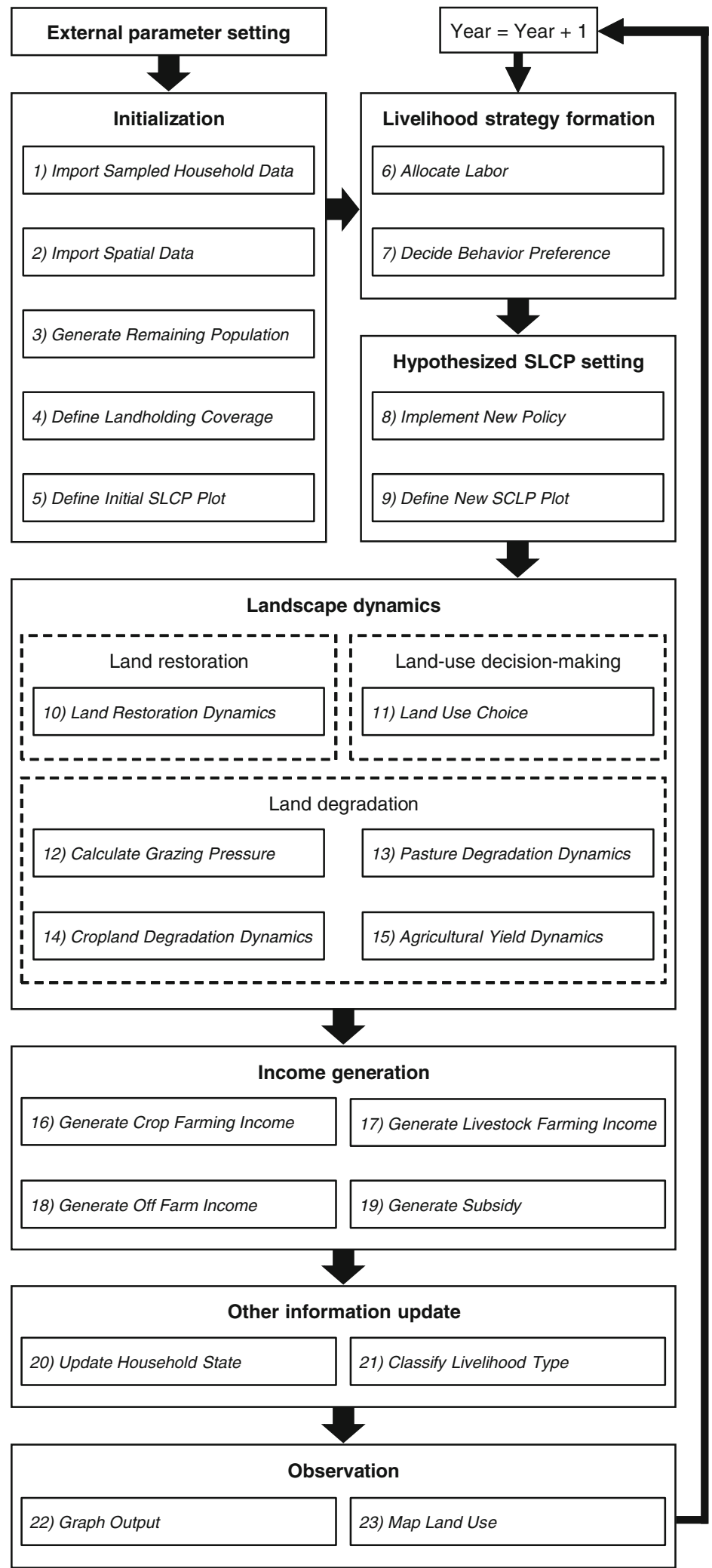


Table 2 Brief descriptions of the procedures and sub-models of IM-LUDAS

\begin{tabular}{ll}
\hline Procedure and sub-model & Brief description \\
\hline $\begin{array}{l}\text { Initialization } \\
\text { (1) Import sampled } \\
\text { household data }\end{array}$ & Imports household demographic data collected in the field \\
(2) Import spatial data & Imports spatial data derived from GIS, remote sensing, and field surveys \\
(3) Generate remaining & Generates the remaining population and defines the central location of their landholdings using \\
population & spatially bounded-random rules with the sampled household data \\
(4) Define landholding & Defines the spatial coverage of landholdings of every household using spatially bounded-random \\
coverage & rules with the sampled household data \\
(5) Define initial SLCP plot & Defines the location and coverage of plots initially assigned by the Sloping Land Conversion \\
& Program (SLCP) according to local implementation rules
\end{tabular}

Livelihood strategy formation

(6) Allocate labor

(7) Decide behavior preference

Hypothesized SLCP setting

(8) Implement new policy

(9) Define new SLCP plot

Landscape dynamics

(10) Land restoration dynamics

(11) Land use choice

(12) Calculate grazing pressure

(13) Pasture degradation dynamics

(14) Cropland degradation dynamics

(15) Agricultural yield dynamics

Income generation

(16) Generate crop farming income

(17) Generate livestock farming income

(18) Generate off farm income

(19) Generate subsidy

Other information update

(20) Update household state

(21) Classify livelihood type

Observation

(22) Graph output

(23) Map land use
Annually defines the labor allocation of each household to different activities (i.e., crop farming, livestock farming, non-farming, and tree planting), on the basis of livelihood type

Annually decides the coefficients of households' land-use decision sub-models with slight variation within own livelihood type (based on standard error)

Annually executes a new policy according to external parameters set by the user

Annually defines participating households and the location and coverage of their SLCP plots according to external parameters set by the user

Annually estimates vegetation and soil properties on the basis of different restoration measures, topographic types, and restoration periods, and can change land-use types accordingly

Annually makes decisions on land use with reference to the allocated labor force, the number of owned livestock, topographic types, and distance between a household's house and each pixel of its own land

Annually calculates grazing pressure from the area of pasture and the number of grazed livestock

Annually estimates vegetation and soil properties on the basis of the grazing pressure, topographic types, and grazing periods, and can change land-use types accordingly

Annually estimates vegetation and soil properties on the basis of the types of cropland and topography and cultivation periods

Annually estimates crop yields on the basis of the types of cropland and topography and cultivation periods, and can change land-use types accordingly

Annually calculates crop-farming income from crop yields.

Annually calculates livestock-farming income from the number of livestock owned, which can be changed on the basis of the area of available pasture

Annually calculates off-farm income with reference to the labor force allocated to off-farm livelihood

Annually calculates the amount of subsidy that participating households receive according to the area of their SLCP plots

Annually updates household profiles

Annually re-categorizes households into the most suitable livelihood types on the basis of their updated profiles. If the livelihood type has changed, the labor-allocation rule is updated accordingly

Annually draws graphs of updated system performance indicators

Annually shows an updated land-use map 


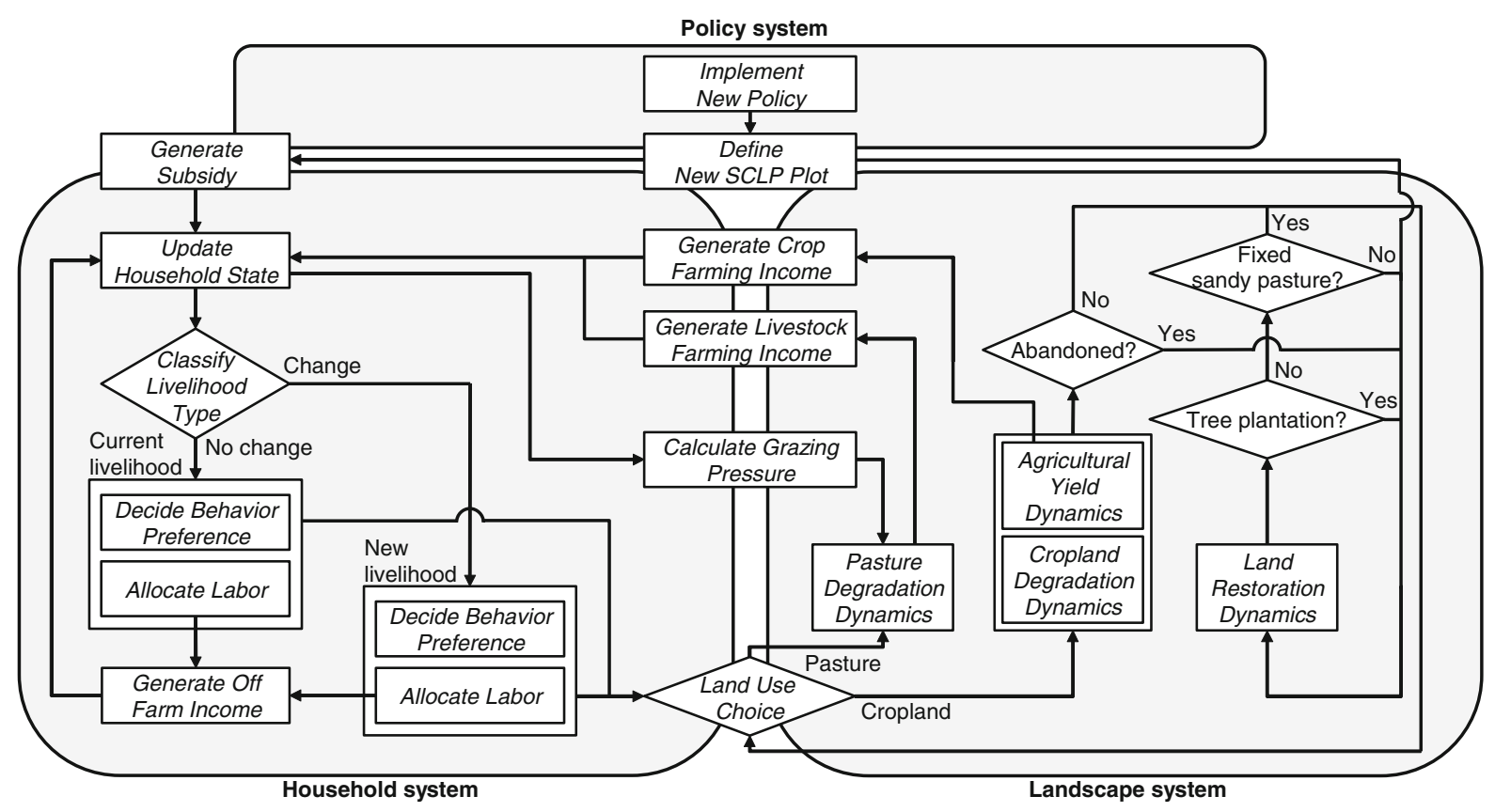

Fig. 2 Schematic overview of key human-environment dynamics in IM-LUDAS including feedback mechanisms. Procedures and sub-models are indicated in italics

feedback loops-which can induce delayed, dislocated, and unintended system changes (Scholz 2011b) —is crucial to understand the spatio-temporal trade-offs of ecosystem services. We also employed the Land Use Dynamic Simulator (LUDAS) (Le 2005; Le et al. 2008, 2010, 2012) as the initial modeling framework for further development and context-based specification. LUDAS's agent-based structure incorporates social-ecological heterogeneity and interactions, bridging organizational, spatial, and temporal couplings (Liu et al. 2007b). This structure enables the generation of secondary feedback loops from the spatial and temporal nesting of householdand plot-specific interactions.

On the basis of those conceptual and practical frameworks, IM-LUDAS includes social-ecological feedback mechanisms at two levels. At a primary (reactive and short-term) level, household and landscape agents both adapt to their current social or ecological conditions by performing the corresponding decision or biophysical sub-models. At a secondary (accumulative and longer-term) level, those agents can shift their internal mechanisms in response to major changes in the patterns of their attributes. Following major changes, if land-use type is converted, then the landscape agent shifts its biophysical sub-model; if livelihood type is changed, the household agent shifts the decision sub-model accordingly (Fig. 2). These types of feedback occur through the above-mentioned hierarchy characterized by human and environmental aggregate levels, including land pixels, households and their landholdings, and village population and landscapes (see "Interaction" and "Collectives" sections for details).

The biophysical sub-models representing agricultural yields and land degradation and restoration-i.e., changes in vegetation structure and soil physiochemical properties-are based on empirical observations and statistical inference (Okuro 1997; Miyasaka et al. 2011, 2014). The decision sub-models are based on an assumption of social psychology: people's behavior is influenced by or learnt from other people with similar conditions. In other words, it is influenced by "imitation," a social process derived from social learning theory (Bandura 1977). Since people tend to be involved in this social process if they are uncertain about their decision outcomes (Festinger 1954) and have low satisfaction levels (or high aspiration levels) (Jager et al. 2000), this theory is suitable for representing adaptive behavior of peasant farmers living in 
a semi-arid region of a developing country, where both ecological and socioeconomic conditions are unstable. The decision sub-models were built with empirical data as well as the biophysical sub-models. All data were collected through crop, vegetation, soil, or household surveys that we conducted in the study area.

Individual decision-making Decision-making is modeled at the household level. Household agents calculate the utility (expressed in terms of probability) for all land-use and location options within their landholdings (except for unavailable land, being tree plantations and shifting sandy pasture), and select the option with the highest utility. They may not, however, select the best land use or location, as often seen in reality, on the basis of an ordered-choice algorithm (Le et al. 2008). The ordered-choice algorithm consists of the following steps: (1) rank the probabilities calculated for all land-use options at a given location, in descending order; (2) try the option ranked first with the success rate of the probability in itself; and (3) decide the first option or pick the second one and repeat the process, depending on the success of the first try.

The decision models explicitly consider household states and perceived landscape information as explanatory variables. Landscape change can be brought about not only by natural processes (e.g., vegetation change under succession) but also by anthropogenic processes (e.g., vegetation change under land use) and change household states in turn. Thus the household agents adapt their behavior to interactive internal and external changes. They also adapt to exogenous policy settings made by users of IM-LUDAS.

A spatial aspect plays a role in the decision process, as mentioned above. A temporal aspect also comes into the decision process, which is based on temporally changing household and landscape states. In addition, accumulated changes in household states can shift its livelihood type (see "Learning" section).

Uncertainty is explicitly included in the agents' decision rules: the lower and upper bounds of the uncertainty range of decision model parameters are defined by standard error, calculated from empirical household data.

Learning In response to major changes in household agents' states during a simulation, they can shift their livelihood type (i.e., their labor-allocation and landuse decision rules) to more closely match households having states similar to their current ones. This represents the imitation process.

Individual sensing In the land-use decision, i.e., the Land Use Choice sub-model, the household agents sense and consider endogenous variables (land availability of their landholdings, SLCP-plot code, number of their own livestock, their labor budget and livelihood type, and probability of land-use options being chosen in every available land pixel of their landholdings and labor force required for the settled land-use types, both of which are calculated in the process of their land-use decision) and exogenous variables (ownership code, ownership code and topographic types of landholdings, and land accessibility defined as distance between a house and each pixel of its landholdings). Late in the simulation, specifically in the Classify Livelihood Type sub-model (Figs. 1,2), the household agents sense some of their updated endogenous state variables (age, labor force, and income structure) and exogenous ones (ethnic group, educational level, and leadership), shown in Table 1, and shift the livelihood type if the change in those variables is large enough.

The spatial scale of sensing is local because the household agents can only know their own states and the states of the landscape agents linked to them via common ownership code. All of the variables the household agents sense to execute their land-use decisions are obtained without error. The agents simply know them, and the cost for sensing is not explicitly included.

Individual prediction There is no individual prediction.

Interaction The household and landscape agents interact directly: the household agent decides land use on the basis of both agents' information, as mentioned above; the landscape agent adapts to the decided land-use type by performing a corresponding biophysical sub-model; the landscape states altered by the biophysical sub-model affect the owner's states and possibly change its land-use decision sub-model; and if the land-use type is changed, the landscape agent shifts its biophysical sub-model accordingly. Those interactions between the household and landscape agents depend on the local land-tenure system. 
The household agents influence each other indirectly through a collective grazing activity. In the Han villages, where pasture is used communally (see "Collectives" section for details), livestock from each household are grazed collectively. The quality and quantity of pasture affected by the collective grazing influence each household's livestock number.

Collectives In each of the Han villages, the households that owned livestock belonged to the group that collectively grazed all of their livestock. Although all pasture was distributed to households in both Mongolian and Han villages, all pasture in the Han villages was communally used in reality. In IMLUDAS, according to this local grazing system, the households in the Mongolian villages graze their livestock within their own pasture, and grazing pressure is calculated based on the number of head of their livestock and the area of their pasture. In the Han villages, on the other hand, grazing pressure is calculated based on the total number of livestock and the entire pasture area in each village; however, households can manage their own livestock on their own (i.e., adjust the number of livestock), considering the pasture conditions determined by the aggregate grazing. The indirect interaction among the household agents occurs in this manner.

Heterogeneity The household and landscape agents are both heterogeneous. The land-use decision submodels differ among the household agents according to their livelihood types. The biophysical sub-models differ among the landscape agents according to landuse type, topographic type, or grazing pressure.

Stochasticity Stochasticity is used to initialize household population, landholdings, and SLCP plots and to determine the parameters of some sub-models and the variables that can fluctuate, such as retirement age and annual labor force of each household. All of the randomization procedures are restricted by predefined spatial or statistical bounds, which are based on empirical observations.

Observation Outputs of IM-LUDAS include annually updated land-use maps and graphs that show temporal changes in the following: land use, income (mean, composition, and equality), cost of the SLCP (sum of subsidy paid), and households' livelihood types - the aforementioned all at two aggregate levels (i.e., the entire study area, and each constituent village); and in biophysical properties (plant species diversity and soil physiochemical properties) at SLCP plots. All the landscape and livelihood changes observed at any aggregate levels emerge from two interrelated agent-based processes by the household and landscape agents.

\section{Details}

Implementation details IM-LUDAS is coded with NetLogo 5.0.4. The model can be made available upon request.

Initialization The initial landscape is given by importing the following GIS data that represent the actual landscape in the initial year (Import Spatial Data procedure): land-use, topography, villageboundary, and sampled household landholding maps. The initialization of the household population consists of three steps (Import Sampled Household Data, Generate Remaining Population, and Define Landholding Coverage procedures), which are detailed in Le et al. (2008, 2010). The initial SLCP plots are spatially decided according to the actual policy rule in the study area (see the descriptions of the study area and Define Initial SLCP Plot procedure in Appendix 1 for details).

Input data Input for simulations can be classified into two types: data and parameters. The data consists of GIS and sampled household data in the form of text to initialize the landscape and household population. All the data were collected by our household surveys or were processed by our remote sensing and GIS analyses (Miyasaka et al. 2016). The parameters can be further broken into calibrated and the user's defined parameters. Most calibrated parameters are coefficients of the sub-models representing land-use decisions and biophysical dynamics. These parameters were calibrated and validated from our field studies. The input parameters set by users relate to the SLCP, except for the total population, enabling users to test their own questions on the policy, including its cost-effectiveness: agricultural criteria for selecting target plots (i.e., crop yields as thresholds to select degraded cropland to be targeted), an economic criterion for selecting target households 
(i.e., household income as a threshold to select the poor, who may need to be targeted under the policy), the amount of subsidy, and implementation period. Crop yields and household income are indicators measured easily. Ease of measurement is a practical advantage in policy implementation. Different agricultural criteria can be set for each of three cropland types (i.e., maize cropland on flat sandy lands, maize cropland on lowlands, and bean-centered cropland on sand dunes). Expected yields differ between them. Cropland whose yields dropped below the user-set agricultural criteria was converted immediately to tree plantation.

Sub-models We built IM-LUDAS on the framework of LUDAS, modifying components and creating new features to fit the study area and achieve our objectives. The model's procedures and sub-models are summarized in Figs. 1 and 2 and Table 2 and detailed in Appendix 1. Those parameters are shown in Appendices 2, 4, and 5.

\section{Model validation}

As suggested by various studies (e.g., Forrester and Senge 1980; Nguyen et al. 2007; Le et al. 2012), open system models with a human behavior componentsuch as an agent-based model for the complex H-E system-should be tested by continuous reviews with multiple criteria rather than a straightforward evaluation of numerical fits between simulated and observed patterns, in order to inform the user of the model's usefulness and increase the user's confidence in the model. The multiple criteria include (1) suitability of the model for its objectives, (2) plausibility of the assumptions and theories the model is based on, (3) validity of internal mechanisms (e.g., sub-models) in the model, (4) validity of input data, and (5) validity of model outputs (Scholz and Tietje 2002; North and Macal 2007; Le et al. 2012). We mention the first and second criteria in the introduction and model description parts of the paper, and in the Appendices we show the statistical validity of the land-use decision and biophysical sub-models based on empirical input data derived from our substantial field investigations. The next section of this paper will indicate the robustness of IM-LUDAS's outputs by demonstrating complex but rational socioeconomic dynamics with statistically explicit uncertainties based on multiple simulation runs.

\section{Simulation experiments}

\section{Scenarios}

Our research question for building IM-LUDAS is as follows: "Can the Sloping Land Conversion Program (SLCP) better achieve its multiple goals, including economic structural shift, if targeting strategies based on social and ecological heterogeneity are incorporated into it?" The simulation experiments in this paper, however, primarily aimed to demonstrate the capability of IM-LUDAS to answer the research question on the basis of the assessment of multidimensional trade-offs in ecosystem services, rather than trying to deliberate in detail on alternate policy plans or a wide range of targeting strategies. To this end, we simply compared two scenarios: S1, a baseline scenario where the current SLCP is implemented as-is, indicating that no targeting strategy is adopted; and S2, a targeting scenario in which an SLCP that incorporates an intensive targeting strategy is implemented. Each scenario was assessed by 10 simulation runs, so that the policy consequences could be represented by the mean values of time-series performance indicators with their uncertainty levels measured by confidence intervals.

Baseline scenario (S1): This scenario is based on the status quo policy situation as it was in 2010: the first round of the SLCP had been executed in only two of the Mongolian villages from 2003 to 2010; the second round is executed in the same villages from 2011 to 2018; during the second round, the SLCP plots under the first round are kept and subsidized, whereas additional SLCP plots are not assigned; the amount of the compensation halves in the second round; implementation plots are selected preferentially from flatlands, which generally have better land conditions than sand dunes; and no criteria are applied for selecting participating households.

Targeting scenario (S2): Although the first round of the SLCP is executed as in S1, an SLCP incorporating an intensive targeting strategy is implemented starting in 2011, instead of the second round. The amount of subsidy and the implementation period are the same as in S1. This altered SLCP does not adopt any criteria for selecting households, but targets cropland with yields below the user-set agricultural criteria. We empirically calculated the lowest profitable limits of crop yields for every cropland type in light of required 
production costs. The agricultural criteria of $\mathrm{S} 2$ are set to the limit yields plus yields equivalent to the amount of subsidy, because stopping cultivation and receiving a subsidy is more profitable for households when the yields drop below the agricultural criteria mentioned above. The resultant criteria were 220 yuan per $т и$ for maize cropland on flat sandy lands, 185 yuan per for maize cropland on lowlands, and 20 yuan per $m u$ for bean-centered cropland. The implementation plots in the first round are treated as unsubsidized tree plantations from 2011. The "intensive" aspect of the strategy is that no limit of implementation plot area is set per household. This intensive execution was introduced in order to better capture the potential of the policy; for example, the expected effect on economic structural shift could be augmented through unlimited land conversion from cropland to tree plantations.

\section{Results and discussion}

\section{Multi-dimensional trade-offs in ecosystem services}

The effectiveness of vegetation and soil restoration in converted tree plantations was higher in $\mathrm{S} 2$ than in $\mathrm{S} 1$; for instance, the diversity of understory herbaceous plant species expressed by Shannon's diversity index $\left(H^{\prime}\right)$ increased in S2, though it had decreased over time in $\mathrm{S} 1$ (Fig. 3). Plant species diversity increases in line with the progress of land restoration in this area, but it declines in the final stage of the restoration process,

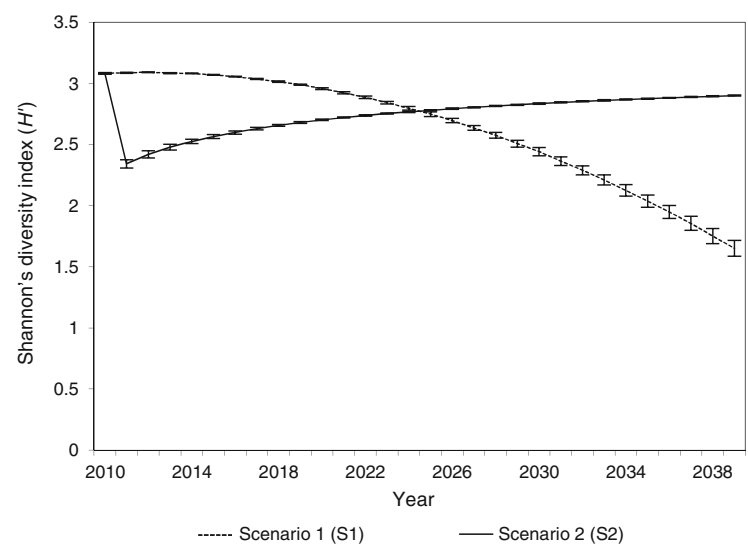

Fig. 3 Change in plant species diversity expressed by Shannon's diversity index $\left(H^{\prime}\right)$ in SLCP-induced tree plantations under scenarios 1 (S1) and 2 (S2). Vertical bars indicate the confidence intervals of the mean values $(95 \%, n=10)$ because a limited number of species becomes dominant and the conditions stabilize (Miyasaka et al. 2014). High values in early times under S1 demonstrated that most tree plantations in S1 were considerably well restored already during the first round of the SLCP or were not degraded originally at the beginning of the policy due to the local rules for site selection (i.e., flatland priority). Conversely, tree plantations in S2 were getting restored during the simulation period, indicating that degraded cropland was targeted well. Although tree plantations are not allowed to be converted to another land use at present, restored land has potential to be used as cropland or pasture in the future. This result shows that the subsidy was used more effectively with respect to land restoration in S2, and in that sense, the targeting strategy worked. There was a dramatic reduction in S2, which can be explained by the fact that the first round of the SLCP was implemented in both S2 and S1 in 2010, but in the subsequent years, the altered SLCP was implemented only in S2. Since the altered policy only targeted degraded cropland with low yields, the initial condition (including plant species diversity) of tree plantations converted from the degraded cropland was poor on average. That is why the value was initially low under S2.

Significantly different patterns of land-use change were obtained between S1 and S2 (Fig. 4a). The area of tree plantations increased greatly in S2, indicating that cropland conversion based on productivity decline (i.e., cropland degradation) was extensive. The area of semi-fixed and fixed sandy pasture and cropland under S2 gradually declined to values lower than under S1 with the large increase of the area of tree plantations. The households abandoned (in S1) or converted (in S2) unprofitable cropland and cultivated other land if they still had land suitable for cultivation. The abandoned land was gradually restored from shifting sandy pasture to semi-fixed and fixed sandy pasture, whereas cropland whose yields dropped below the agricultural criteria was converted immediately to tree plantation, which then could not be used for any other purpose. Consequently, the area of pasture decreased as the area of tree plantations increased significantly. According to Miyasaka et al. (2011), bean-centered cropland on sand dunes is susceptible to wind erosion and becomes degraded more quickly than other types of cropland. Because semi-fixed sandy pasture tends to be located in sand 

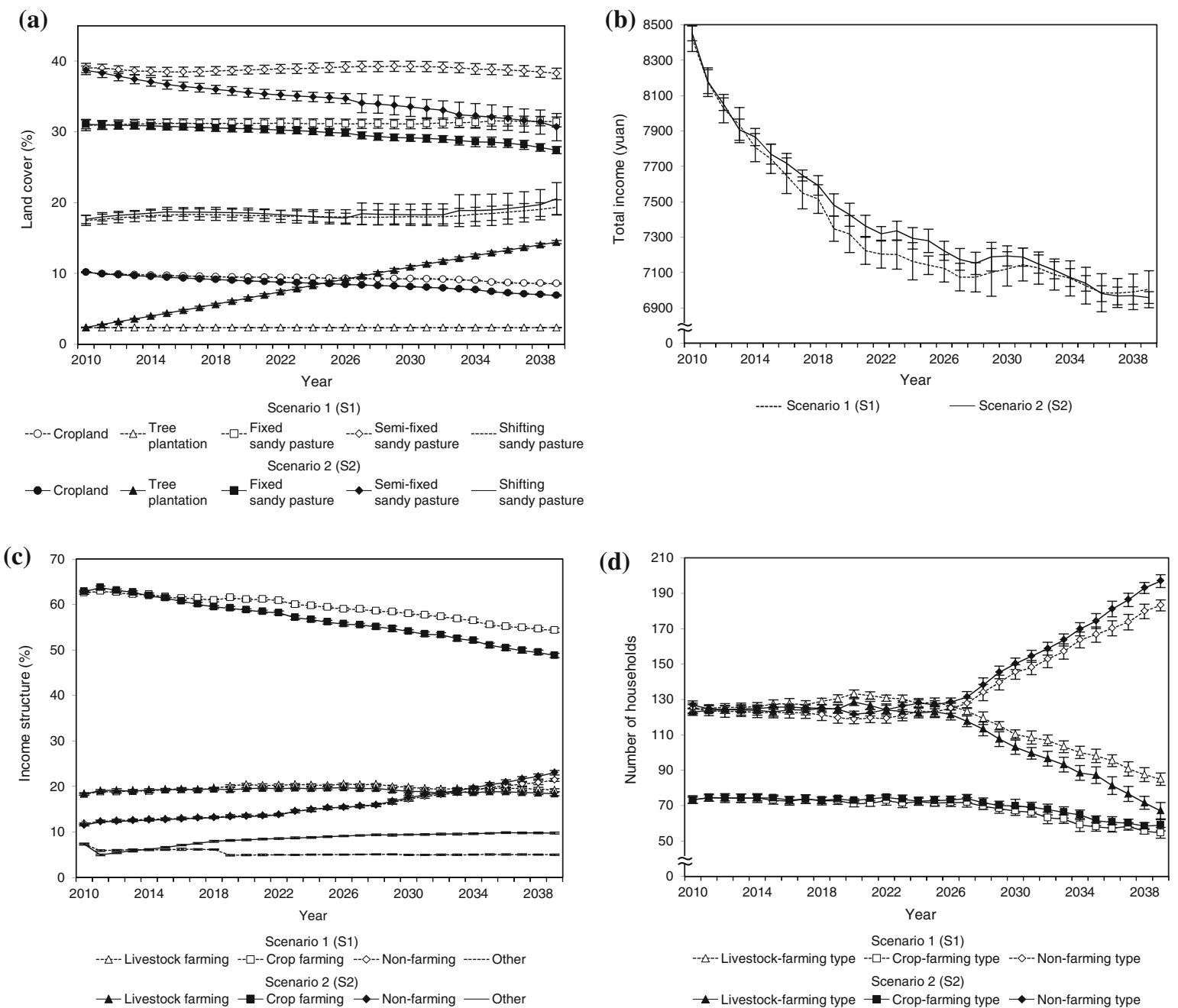

Fig. 4 Land-use change under scenarios 1 (S1) and 2 (S2) (a), change in average total income under S1 and S2 (b), change in income structure under S1 and S2 (c), and change in the number

dunes, cropland conversion occurred more often there, which led to a larger decline in the area of semi-fixed sandy pasture than the decline of fixed sandy pasture. The higher rate of reduction of cropland area in S2 is attributed to the fact that some households could not find land suitable for cultivation within their landholdings as tree plantations were expanding. These observed patterns of land-use change demonstrate time lags or legacy effects, which are a typical feature explaining the non-linear dynamics of complex systems (Liu et al. 2007a, b), reflecting the heterogeneity of the landscape and households.

of households in each livelihood type under S1 and S2 (d). Vertical bars indicate the confidence intervals of the mean values $(95 \%, n=10)$

Although it cannot be seen in the graph of land-use change in the entire study area (Fig. 4a), the area of shifting sandy pasture clearly expanded in S2 at the household and village scales: patches of shifting sandy pasture were produced in the Mongolian villages where pasture land was distributed to every household (Fig. 5a); an abrupt increase in the area of shifting sandy pasture or an abrupt decrease in the area of fixed and semi-fixed sandy pasture was detected in one Han village where all pasture was communal (Fig. 5b). The former result is due to increased grazing pressure around tree plantations within the landholdings of 
(a)
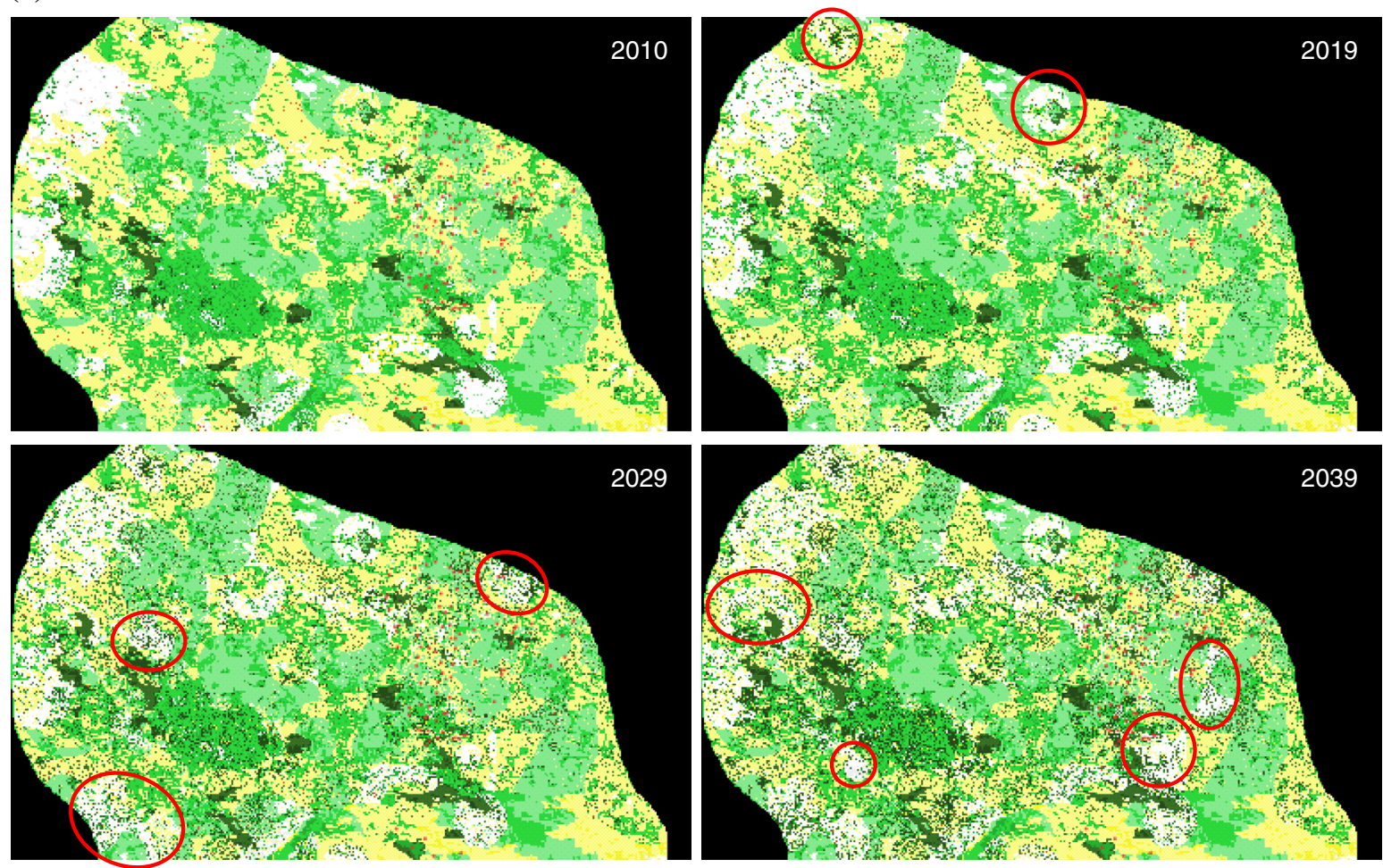

$\square$ Tree

Tree $\quad \square$ Fixed

plantation

sandy pasture

Semi-fixed

sandy pasture

Shifting

sandy pasture

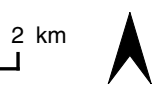

(b)

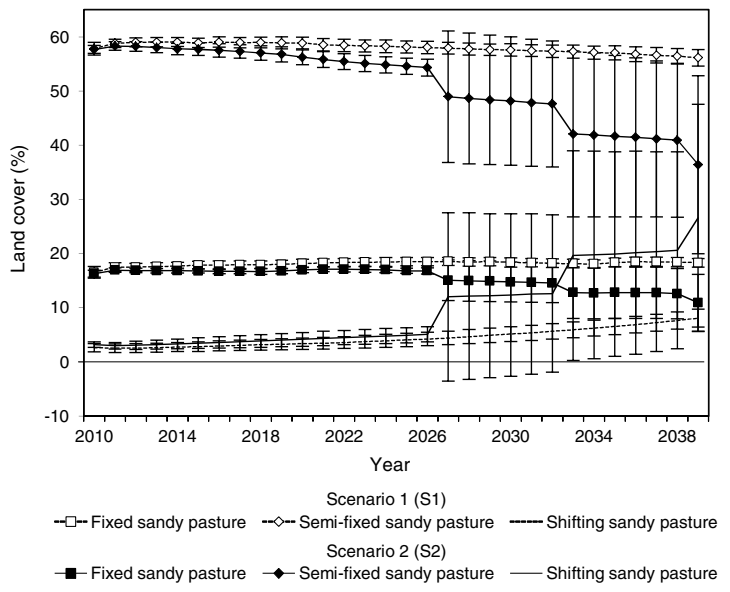

Fig. 5 Subset images showing the expansion of shifting sandy pasture in the form of patches highlighted by red circles in Mongolian villages (a) and change in the area of fixed, semi-

each participating household, with the pressure having resulted from the large increase in the area of tree plantations and accompanying pasture loss. Grazing fixed, and shifting sandy pasture in a Han village under scenarios 1 (S1) and 2 (S2) (b). Vertical bars indicate the confidence intervals of the mean values $(95 \%, n=10)$

pressure was different for each household's landholdings, so shifting sandy pasture expanded in the form of patches. The latter result shows that the increased 
pressure was dispersed across the entire communal pasture, but on the other hand, a large area of land was abruptly degraded once a threshold of grazing pressure was exceeded. The observed abrupt change was partly due to the three-level classification of grazing pressure we adopted to model pasture degradation (see the description of Pasture Degradation Dynamics submodel in Appendix 1), but change in the real world would probably be smoother. The result, however, still suggests that this type of degradation could happen in communally-used pasture. When it comes to model behavior, the abrupt change in 2027, 2033, and 2039 with long confidence intervals in Fig. 5b means that the change took place three times out of 10 simulation runs. If we run another 10 simulations, the change will most likely happen in different years. Although vegetation and soil properties within tree plantations were ameliorated, as mentioned above, the intensive application of SLCP can have the negative externalities outside the target plots. These results represent spatial and temporal trade-offs at multiple scales, including cross-scale, threshold-related feedback (Verburg 2006), which is also characteristically found in complex systems (Verburg 2006; Liu et al. 2007a, b).

Average total income kept decreasing in both S1 and S2 (Fig. 4b). The continual decline in crop productivity of each farmland area largely contributed to this income loss, because the major income source was crop farming (Fig. 4c). The average income under $\mathrm{S} 1$ was significantly lower than under $\mathrm{S} 2$ in the middle of the simulation period, but eventually returned to the same level. This result would be mainly due to a combination of the following three reasons: subsidy termination, reduction in cropland area, and structural change in the economy. Since SLCP plots were not newly assigned in S1, subsidy provision was completely stopped in 2019, eight years after the start of the second round of the SLCP. This dynamic temporarily expanded the income gap between the two scenarios. In addition to the consecutive decline in crop yields, cropland area also decreased gradually during the simulations (Fig. 4a), and this trend was stronger in S2 than in S1 due to the large amount of afforestation. This larger reduction in the major income source caused further decreases in the average income under S2, particularly later in the simulations. A structural shift from an agricultural economy to a non-agricultural economy occurred in both $\mathrm{S} 1$ and $\mathrm{S} 2$
(Fig. 4d). The rise in the number of non-farming households, particularly during the last 12 years, can be explained by the increase in the number of young households (i.e., generational change), because the younger generations tend to gravitate toward nonfarming livelihoods (Table 1). This change toward the non-farming livelihoods raised off-farm income and would offset the decline in income caused by cropland degradation (Fig. 4c). Although the structural change was slightly more facilitated through cropland conversion in $\mathrm{S} 2$ than in $\mathrm{S} 1$, it did not raise the average income in $\mathrm{S} 2$ above $\mathrm{S} 1$. This is because the facilitation effect on income increase was exceeded by the income loss from the larger reduction in cropland area, as illustrated in Fig. 4c. Consequently, in terms of poverty alleviation, the intensive application of SLCP had a positive effect due to economic structural change, but a greater negative effect due to cropland conversion. The pattern of income change shown in Fig. $4 \mathrm{~b}$ was generated from these complex feedback loops under the different policy scenarios.

All of the results can be summarized in terms of multi-dimensional trade-offs in ecosystem services as follows: the intensive targeting strategy of the SLCP expanded tree plantations and facilitated vegetation and soil restoration (improvement of regulating and provisioning services) and household change toward off-farm livelihoods, as expected (a positive social effect); however, the policy also caused further pasture loss and degradation outside the implementation plots (reduction in regulating and provisioning services), in the form of spatial and temporal trade-offs, including time lags and threshold change; furthermore, the livelihood change facilitated by the policy was too weak to compensate for the income deterioration by the afforestation-induced reduction in cropland (reduction in a provisioning service and its negative social effect). Consequently, in response to the research question, the results indicate that the targeting strategies examined in the present study do not always improve achievement of the environmental or economic goals of the policy.

\section{Capability of IM-LUDAS as a complex H-E model}

The results obtained indicate that IM-LUDAS does recreate complex feedback loops between heterogeneous household and landscape systems. While other spatial modeling approaches currently available 
cannot fully explore the complexity of the H-E systems, including multi-dimensional trade-offs, as reviewed in the Introduction, agent-based modeling $(\mathrm{ABM})$ is still undergoing development to clarify complexities. Parker et al. (2008) summarized three types of linkages between human and environmental systems: single uni-directional, multiple uni-directional, and full, two-way linkages. The implementation of the two-way linkages in coupled $\mathrm{H}-\mathrm{E}$ models is an essential research direction, but previous research has mainly addressed the uni-directional linkages; the development of models that can simulate the two-way linkages is still in progress (Filatova et al. 2013, 2016). IM-LUDAS incorporates a learning process (i.e., imitation) based on behavioral heterogeneity, represented by different livelihood types. This household learning process is reciprocally linked to multiple biophysical processes of pasture and cropland degradation and land restoration. Thus, our model represents such two-way linkages, including secondary and cross-scale feedback loops between human and environmental systems in dryland areas. Then it captures typical characteristics of $\mathrm{H}-\mathrm{E}$ systems such as time lags and threshold change under policy intervention, which earlier research has not shown in a spatiallyexplicit manner.

Empirically-parameterized $\mathrm{ABM}$ is essential for understanding real, complex systems and for providing relevant information for real decision-making (Parker et al. 2003; Berger and Schreinemachers 2006; Valbuena et al. 2008). However, one of its drawbacks is that purely empirical models cannot embed what never existed in reality. Our study, for example, empirically examined three household livelihood types, but other major livelihood types could come up in the near future. Since all three types depended on crop-farming to some extent, the local economy was greatly affected by changing land conditions, even though the economic structure changed in an expected direction. This dynamic suggests that the shift from an agricultural to a non-agricultural economy could not be fully explored in this simulation, as only the present livelihood types are considered. In the future, we may need to use not only hypothetical policy scenarios as external change, but also hypothetical entities as model components in empirical ABM to better assess and support real decision-making. We should note, of course, that introducing too many hypothetical entities diminishes the advantage of an empirical model and makes the model less suitable for real decisionmaking.

\section{Conclusions}

We constructed a spatial agent-based model, named IM-LUDAS (Inner Mongolia Land Use Dynamic Simulator), that represents a human-environment (H-E) system composed of heterogeneous household and landscape agents and their multi-scale interactions. With IM-LUDAS, empirically calibrated for a semi-arid region in Inner Mongolia, China, we tested the complex effects of a payment for ecosystem services (PES) program, called the Sloping Land Conversion Program (SLCP), on local household livelihoods, land degradation, and land restoration, by comparison of hypothetical conditions to the actual SLCP. Our simulations showed that the SLCP could potentially result in multi-dimensional (spatial, temporal, and social) trade-offs in dryland ecosystem services, depending on the intensity of policy implementation. This result implies, in response to our research question ("Can the Sloping Land Conversion Program better achieve its multiple goals, including economic structural shift, if targeting strategies based on social and ecological heterogeneity are incorporated into it?"), that the targeting strategies examined do not always improve achievement of the environmental or economic goals of the policy.

Our model incorporates two-way linkages to represent complex feedback loops between households' heterogeneous behavior and multiple biophysical processes. Previous agent-based models left room for improvements in modeling of socio-ecological and spatio-temporal patterns, including time lags and threshold change. IM-LUDAS has proven itself an advanced example of empirical models that can recreate essential features of complex H-E systems.

Although this paper employs only one hypothetical scenario, IM-LUDAS can assess diverse scenarios, dealing with a wide range of targeting strategies and policy costs under the SLCP, thanks to its ability to represent social-ecological heterogeneity. Furthermore, this model can easily be customized for other purposes, embedding other hypothetical agents if necessary, as its agent-based structure has built-in flexibility. Further research could test and further demonstrate the capacity of IM-LUDAS to be 
customized. As one of the first spatially-explicit models to represent a dryland H-E system, IMLUDAS has the potential to contribute to a variety of simulations relating to complex phenomena and challenges in desertified regions.

Acknowledgements The authors express their appreciation to all the staff and students of the Naiman Desertification Research Station of the Chinese Academy of Sciences for their kind help with field surveys, Roland W. Scholz for his kind acceptance and hosting of a study visit at Natural and Social Science Interface, ETH Zurich, and anonymous reviewers for their critical review and comments on the draft of this manuscript. This study was supported by a Grant-in-Aid for Japan Society for the Promotion of Science (JSPS) fellows (20-7493), with additional support from the Global Environmental Research Fund (G-071) and Environment Research and Technology Development Fund (4-1407) of Japan's Ministry of the Environment and the Funds for Integrated Promotion of Social System Reform and Research and Development from Japan's Ministry of Education, Culture, Sports, Science and Technology awarded to Keio University's International Program for Environmental Innovators.

Open Access This article is distributed under the terms of the Creative Commons Attribution 4.0 International License (http:// creativecommons.org/licenses/by/4.0/), which permits unrestricted use, distribution, and reproduction in any medium, provided you give appropriate credit to the original author(s) and the source, provide a link to the Creative Commons license, and indicate if changes were made.

\section{References}

Bandura A (1977) Social learning theory. Prentice-Hall, Englewood Cliffs

Bennett EM, Cramer W, Begossi A, Cundill G, Díaz S, Egoh B, Geijzendorffer IR, Krug CB, Lavorel S, Lazos E, Lebel L, Martín-López B, Meyfroidt P, Mooney HA, Nel JL, Pascual U, Payet K, Harguindeguy NP, Peterson GD, PrieurRichard A-H, Reyers B, Roebeling P, Seppelt R, Solan M, Tschakert P, Tscharntke T, Turner BL, Verburg PH, Viglizzo EF, White PCL, Woodward G (2015) Linking biodiversity, ecosystem services, and human well-being: three challenges for designing research for sustainability. Curr Opin Environ Sustain 14:76-85

Berger T, Schreinemachers P (2006) Creating agents and landscapes for multiagent systems from random samples. Ecol Soc 11:19

Binder CR, Hinkel J, Bots PWG, Pahl-Wostl C (2013) Comparison of frameworks for analyzing social-ecological systems. Ecol Soc 18:26

Boulanger PM, Brechet T (2005) Models for policy-making in sustainable development: the state of the art and perspectives for research. Ecol Econ 55:337-350

Carpenter SR, DeFries R, Dietz T, Mooney HA, Polasky S, Reid WV, Scholes RJ (2006) Millennium Ecosystem Assessment: research needs. Science 314:257-258
Carpenter SR, Mooney HA, Agard J, Capistrano D, Defries RS, Díaz S, Dietz T, Duraiappah AK, Oteng-Yeboah A, Pereira HM, Perrings C, Reid WV, Sarukhan J, Scholes RJ, Whyte A (2009) Science for managing ecosystem services: beyond the Millennium Ecosystem Assessment. Proc Natl Acad Sci USA 106:1305-1312

Chen XD, Lupi F, Vina A, He GM, Liu JG (2010) Using costeffective targeting to enhance the efficiency of conservation investments in payments for ecosystem services. Conserv Biol 24:1469-1478

de Groot RS, Alkemade R, Braat L, Hein L, Willemen L (2010) Challenges in integrating the concept of ecosystem services and values in landscape planning, management and decision making. Ecol Complex 7:260-272

Díaz S, Demissew S, Carabias J, Joly C, Lonsdale M, Ash N, Larigauderie A, Adhikari JR, Arico S, Báldi A, Bartuska A, Baste IA, Bilgin A, Brondizio E, Chan KMA, Figueroa VE, Duraiappah A, Fischer M, Hill R, Koetz T, Leadley P, Lyver P, Mace GM, Martin-Lopez B, Okumura M, Pacheco D, Pascual U, Pérez ES, Reyers B, Roth E, Saito O, Scholes RJ, Sharma N, Tallis H, Thaman R, Watson R, Yahara T, Hamid ZA, Akosim C, Al-Hafedh Y, Allahverdiyev R, Amankwah E, Asah ST, Asfaw Z, Bartus G, Brooks LA, Caillaux J, Dalle G, Darnaedi D, Driver A, Erpul G, Escobar-Eyzaguirre P, Failler P, Fouda AMM, Fu B, Gundimeda H, Hashimoto S, Homer F, Lavorel S, Lichtenstein G, Mala WA, Mandivenyi W, Matczak P, Mbizvo C, Mehrdadi M, Metzger JP, Mikissa JB, Moller H, Mooney HA, Mumby P, Nagendra H, Nesshover C, OtengYeboah AA, Pataki G, Roué M, Rubis J, Schultz M, Smith P, Sumaila R, Takeuchi K, Thomas S, Verma M, YeoChang Y, Zlatanova D (2015) The IPBES Conceptual Framework-connecting nature and people. Curr Opin Environ Sustain 14:1-16

Festinger L (1954) A theory of social comparison processes. Hum Relat 7:117-140

Filatova T, Polhill JG, van Ewijk S (2016) Regime shifts in coupled socio-environmental systems: review of modelling challenges and approaches. Environ Modell Softw 75:333-347

Filatova T, Verburg PH, Parker DC, Stannard CA (2013) Spatial agent-based models for social-ecological systems: challenges and prospects. Environ Manage 45:1-7

Forrester JW, Senge PM (1980) Tests for building confidence in system dynamics models. In: Legasto AA Jr, Forrester JW, Lyneis JM (eds) System dynamics: TIMS studies in management sciences, vol 14. North-Holland Publishing Company, Amsterdam, pp 209-228

Gauvin C, Uchida E, Rozelle S, Xu J, Zhan J (2010) Costeffectiveness of payments for ecosystem services with dual goals of environment and poverty alleviation. Environ Manage 45:488-501

Holling CS (2001) Understanding the complexity of economic, ecological, and social systems. Ecosystems 4:390-405

Jager W, Janssen MA, De Vries HJM, De Greef J, Vlek CAJ (2000) Behaviour in commons dilemmas: Homo economicus and Homo psychologicus in an ecological-economic model. Ecol Econ 35:357-379

Kelly RA, Jakeman AJ, Barreteau O, Borsuk ME, ElSawah S, Hamilton SH, Henriksen HJ, Kuikka S, Maier HR, Rizzoli AE, van Delden H, Voinov AA (2013) Selecting among 
five common modelling approaches for integrated environmental assessment and management. Environ Modell Softw 47:159-181

König HJ, Podhora A, Helming K, Zhen L, Wang C, Wübbeke J, Baumeister T, Du B, Yan H (2014) Confronting international research topics with stakeholders on multifunctional land use: the case of Inner Mongolia, China. iForest 7:403-413

Le QB (2005) Multi-agent system for simulation of land-use and land cover change: a theoretical framework and its first implementation for an upland watershed in the Central Coast of Vietnam: Ecology and Development Series 29. Cuvillier Verlag Göttingen, Göttingen

Le QB (2015) Farming system models for supporting farm resilience: research needs, gaps and promising approaches. In: Gritti ES, Wery J (eds) Proceedings of the 5th international symposium for farming systems design: multifunctional farming systems in a changing world, Montpellier, pp 85-86

Le QB, Park SJ, Vlek PLG (2010) Land Use Dynamic Simulator (LUDAS): a multi-agent system model for simulating spatio-temporal dynamics of coupled human-landscape system 2. Scenario-based application for impact assessment of land-use policies. Ecol Inform 5:203-221

Le QB, Park SJ, Vlek PLG, Cremers AB (2008) Land-Use Dynamic Simulator (LUDAS): a multi-agent system model for simulating spatio-temporal dynamics of coupled human-landscape system. I. Structure and theoretical specification. Ecol Inform 3:135-153

Le QB, Seidl R, Scholz RW (2012) Feedback loops and types of adaptation in the modelling of land-use decisions in an agent-based simulation. Environ Modell Softw 27(28):83-96

Levin SA (1998) Ecosystems and the biosphere as complex adaptive systems. Ecosystems 1:431-436

Li A (2012) Modeling human decisions in coupled human and natural systems: review of agent-based models. Ecol Model 299:25-36

Li Y, Fan M, Li W (2015) Application of payment for ecosystem services in China's rangeland conservation initiatives: a social-ecological system perspective. Rangel J 37:285-296

Li J, Feldman MW, Li S, Daily GC (2011) Rural household income and inequality under the Sloping Land Conversion Program in western China. Proc Natl Acad Sci USA 108:7721-7726

Liu J, Dietz T, Carpenter SR, Alberti M, Folke C, Moran E, Pell AN, Deadman P, Kratz T, Lubchenco J, Ostrom E, Ouyang Z, Provencher W, Redman CL, Schneider SH, Taylor WW (2007a) Complexity of coupled human and natural systems. Science 317:1513-1516

Liu J, Dietz T, Carpenter SR, Folke C, Alberti M, Redman CL, Schneider SH, Ostrom E, Pell AN, Lubchenco J, Taylor WW, Ouyang Z, Deadman P, Kratz T, Provencher W (2007b) Coupled human and natural systems. Ambio 36:639-649

Liu J, Li S, Ouyang Z, Tam C, Chen X (2008) Ecological and socioeconomic effects of China's policies for ecosystem services. Proc Natl Acad Sci USA 105:9477-9482

MA (Millennium Ecosystem Assessment) (2005) Ecosystems and human well-being: current state and trends. Island Press, Washington, DC
Marticorena B, Bergametti G, Gillette D, Belnap J (1997) Factors controlling threshold friction velocity in semiarid and arid areas of the United States. J Geophys Res Atmos 102:23277-23287

Matthews RB, Gilbert NG, Roach A, Polhill JG, Gotts NM (2007) Agent-based land-use models: a review of applications. Landscape Ecol 22:1447-1459

Miyasaka T, Okuro T, Miyamori E, Zhao X, Takeuchi K (2014) Effects of different restoration measures and sand dune topography on short- and long-term vegetation restoration in northeast China. J Arid Environ 111:1-6

Miyasaka T, Okuro T, Zhao X, Takeuchi K (2016) Classification of land use on sand-dune topography by object-based analysis, digital photogrammetry, and GIS analysis in the Horqin Sandy Land, China. Environments 3:17

Miyasaka T, Okuro T, Zhao H, Zhao X, Zuo X, Takeuchi K (2011) Impacts of the local land-use system in a semi-arid region of northeastern China on soil properties, crop growth, and weed communities. J Arid Environ 75:1155-1163

Müller B, Bohn F, Dreßler G, Groeneveld J, Klassert C, Martin R, Schlüter M, Schulze J, Weise H, Schwarz N (2013) Describing human decisions in agent-based modelsODD $+\mathrm{D}$, an extension of the ODD protocol. Environ Modell Softw 48:37-48

Nguyen TG, de Kok L, Titus MJ (2007) A new approach to testing an integrated water systems model using qualitative scenarios. Environ Modell Softw 22:1557-1571

North MJ, Macal CM (2007) Managing business complexity: discovering strategic solutions with agent-based modeling and simulation. Oxford University Press, New York

Okuro T (1997) Studies on the influence of grazing on the land and vegetation degradation and restoration process in grassland regions in northeast China. Ph.D. dissertation, The University of Tokyo, Tokyo (in Japanese with English summary)

Ostrom E (2007) A diagnostic approach for going beyond panaceas. Proc Natl Acad Sci USA 104:15181-15187

Ostrom E (2009) A general framework for analyzing sustainability of social-ecological systems. Science 325 : 419-422

Pagiola S, Arcenas A, Platais G (2005) Can payments for environmental services help reduce poverty? An exploration of the issues and the evidence to date from Latin America. World Dev 33:237-253

Parker DC, Hessl A, Davis SC (2008) Complexity, land-use modeling, and the human dimension: fundamental challenges for mapping unknown outcome spaces. Geoforum 39:789-804

Parker DC, Manson SM, Janssen MA, Hoffmann MJ, Deadman P (2003) Multi-agent systems for the simulation of landuse and land-cover change: a review. Ann Assoc Am Geogr 93:314-337

Rammel C, Stagl S, Wilfing H (2007) Managing complex adaptive systems - a co-evolutionary perspective on natural resource management. Ecol Econ 63:9-21

Reynolds JF, Grainger A, Stafford Smith DM, Bastin G, GarciaBarrios L, Fernández RJ, Janssen MA, Jürgens N, Scholes RJ, Veldkamp A, Verstraete MM, Von Maltitz G, Zdruli P (2011) Scientific concepts for an integrated analysis of desertification. Land Degrad Dev 22:166-183 
Reynolds JF, Stafford Smith DM, Lambin EF, Turner BL, Mortimore M, Batterbury SPJ, Downing TE, Dowlatabadi H, Fernández RJ, Herrick JE, Huber-Sannwald E, Jiang H, Leemans R, Lynam T, Maestre FT, Ayarza M, Walker B (2007) Global desertification: building a science for dryland development. Science 316:847-851

Rodríguez JP, Beard TD Jr, Bennett EM, Cumming GS, Cork S, Agard J, Dobson AP, Peterson GD (2006) Trade-offs across space, time, and ecosystem services. Ecol Soc 11:28

Scholz RW (2011a) Environmental literacy in science and society: from knowledge to decisions. Cambridge University Press, Cambridge

Scholz RW (2011b) The HES postulates. In: Scholz RW (ed) Environmental literacy in science and society: from knowledge to decisions. Cambridge University Press, Cambridge, pp 407-452

Scholz RW, Tietje O (2002) Embedded case study methods: integrating quantitative and qualitative knowledge. Sage, Thousand Oaks

Seppelt R, Dormann CF, Eppink FV, Lautenbach S, Schmidt S (2011) A quantitative review of ecosystem service studies: approaches, shortcomings and the road ahead. J Appl Ecol 48:630-636

State Forestry Administration (2003) Master plan for the Sloping Land Conversion Program. China Forestry Publishing House, Beijing

Sterk G, Haigis J (1998) Farmers' knowledge of wind erosion processes and control methods in Niger. Land Degrad Dev 9:107-114

Turner BL, Kasperson RE, Matson PA, McCarthy JJ, Corell RW, Christensen L, Eckley N, Kasperson JX, Luers A, Martello ML, Polsky C, Pulsipher A, Schiller A (2003) A framework for vulnerability analysis in sustainability science. Proc Natl Acad Sci USA 100:8074-8079

Uchida E, Rozelle S, Xu JT (2009) Conservation payments, liquidity constraints, and off-farm labor: impact of the Grain-for-Green program on rural households in China. Am J Agr Econ 91:70-86

Valbuena D, Verburg PH, Bregt AK (2008) A method to define a typology for agent-based analysis in regional land-use research. Agric Ecosyst Environ 128:27-36

Verburg PH (2006) Simulating feedbacks in land use and land cover change models. Landscape Ecol 21:1171-1183
Verburg PH, Overmars KP (2009) Combining top-down and bottom-up dynamics in land use modeling: exploring the future of abandoned farmlands in Europe with the DynaCLUE model. Landscape Ecol 24:1167-1181

Verburg PH, Erb KH, Mertz O, Espindola G (2013) Land system science: between global challenges and local realities. Curr Opin Environ Sustain 5:433-437

Villamor GB, van Noordwijk M, Le QB, Lusiana B, Matthews R, Vlek PLG (2011) Diversity deficits in modelled landscape mosaics. Ecol Inform 6:73-82

Wang C, Ouyang H, Maclaren V, Yin Y, Shao B, Boland A, Tian Y (2007a) Evaluation of the economic and environmental impact of converting cropland to forest: a case study in Dunhua county, China. J Environ Manag 85:746-756

Wang XH, Lu CH, Fang JF, Shen YC (2007b) Implications for development of grain-for-green policy based on cropland suitability evaluation in desertification-affected north China. Land Use Policy 24:417-424

Whitfield S, Geist HJ, Ioris AAR (2011) Deliberative assessment in complex social-ecological systems: recommendations for environmental assessment in drylands. Environ Monit Assess 183:465-483

Wu J (1999) Hierarchy and scaling: extrapolating information along a scaling ladder. Can J Remote Sens 25:367-380

Wu J (2013) Landscape sustainability science: ecosystem services and human well-being in changing landscapes. Landscape Ecol 28:999-1023

Wu J, David JL (2002) A spatially explicit hierarchical approach to modeling complex ecological systems: theory and applications. Ecol Model 153:7-26

Wu J, Loucks OL (1995) From balance of nature to hierarchical patch dynamics: a paradigm shift in ecology. Q Rev Biol 70:439-466

Yin R, Zhao M (2012) Ecological restoration programs and payments for ecosystem services as integrated biophysical and socioeconomic processes-China's experience as an example. Ecol Econ 73:56-65

Zuo XA, Zhao XY, Zhao HL, Guo YR, Zhang TH, Cui JY (2010) Spatial pattern and heterogeneity of soil organic carbon and nitrogen in sand dunes related to vegetation change and geomorphic position in Horqin Sandy Land, Northern China. Environ Monit Assess 164:29-42 